\title{
SALVADOR ALBACAR, UN MUEBLISTA VALENCIANO EN BARCELONA SALVADOR ALBACAR, A FURNITURE MANUFACTURER FROM VALENCIA IN BARCELONA
}

Julio Vives Chillida* Dr. en Derecho Investigador sobre la industria del mueble curvado

\section{Resumen}

En este artículo se examina un mueblista valenciano de finales del Siglo XIX y principios del XX llamado Salvador Albacar y Gil. Fue un importante fabricante de mueble curvado y decorador de Valencia, participó en la Exposición Regional Valenciana de 1909, tuvo patentes de invención y logró implantar con éxito una sucursal en la calle de Balmes de Barcelona en la década de 1910. Es un buen representante de la burguesía industrial valenciana en aquella época. XIII.

Palabras clave: Albacar, Mueble, Madera curvada, Exposición, Alfonso

\section{Abstract}

In this article we examine a furniture manufacturer: Salvador Albacar y Gil, who was operative in Valencia at the end of XIXth Century and the beginnings of the $\mathrm{XX}^{\text {th }}$. He was an important bentwood furniture manufacturer and decorator in Valencia, and participated in the 1909 Regional Exhibition in the same city, obtained some patents of invention and managed to establish with success a branch in Barcelona (Balmes Street) in the 1910 decade. It's a good example of the industrial bourgeoisie of Valencia in that epoque.

Key-words: Albacar, Furniture, Bent Wood, Exhibition, Alfonso XIII.

\footnotetext{
* E-mail: juliovivesch@yahoo.es
} 


\section{Ideas generales}

La técnica de curvar la madera con fines diversos se conoce desde hace siglos pero su desarrollo desde la perspectiva industrial para hacer muebles, mediante la vaporización de las piezas largas de madera de haya y su inserción en moldes metálicos, se produjo durante el siglo XIX. Entre los ebanistas que desarrollaron la técnica destacó Michael Thonet (Boppard am Rhein, 1796Viena, 1871) que, tras unos inicios en los que practicó el laminado artesanal, estableció en 1853 la empresa Hermanos Thonet con sus cinco hijos y desarrolló una gran industria cuyo nombre, bajo diversas formas, perdura hasta la actualidad. Alrededor del año en que terminó la tercera patente de Thonet, en 1869, se crearon otras empresas en Austria-Hungría que compitieron con Hermanos Thonet, tales como Jacob \& Josef Kohn, en Wsetín (Moravia), y D.G. Fischel Söhne, en Niemes (Bohemia), los principales fabricantes de muebles de Viena, -como llegó a denominarse al mueble curvado-, durante la segunda mitad del siglo XIX y el primer tercio del siglo XX. La casa Kohn es famosa por su colaboración con arquitectos y diseñadores en la elaboración de mueble curvado moderno, principalmente después del 1900, con los nombres de Josef Hoffmann (1870-1956) o Gustav Siegel (1880-1970), entre los más conocidos. En cambio la casa Fischel, especialista en mueble curvado y torneado, no es generalmente conocida, a pesar de que perduró hasta los años treinta como empresa independiente. En España, Fischel tenía su representación principal en Málaga y tuvo gran influencia en la estética de los modelos de sillas y sofás curvados que se hacían en Valencia. El mueble curvado, en general, se ha convertido actualmente en un dato relevante en toda historia del diseño industrial ${ }^{1}$.

Al igual que en otros países europeos, como Alemania e Italia, estos avances en la elaboración de mueble curvado se introdujeron en España en el último tercio del siglo XIX. En Valencia, además de una presencia asentada de la ebanistería tradicional, se conocía la técnica de curvar por la fabricación habitual de toneles de vino, mesas de billar y abanicos, pero el nuevo uso -la fabricación de muebles- se introdujo gracias a las fructíferas relaciones comerciales con Austria-Hungría que tenían lugar especialmente a través del puerto marítimo de El Grao. Es difícil saber quién fue el primero en introducir la fabricación del mueble curvado en Valencia. Se barajan al respecto diversos nombres como José Trobat, Salvador Albacar, Ventura Feliu, Luis Suay, Joaquín Lleó; todos ellos nombres de la importante industria valenciana de mueble curvado ${ }^{2}$. Fueron, en cualquier caso, personajes clave en la industrialización del mueble en Valencia produciendo en serie muebles de consumo para la incipiente clase burguesa y ocupando a cientos de trabajadores en sus fábricas, en las que había división del trabajo. Según decía Martínez Ferrando ya en los años treinta, hacia 1909 había 10.000 obreros en la industria del mueble en Valencia y sus fabricantes “...muestran un sello personal por la sorprendente facilidad de asimilación que poseen los ebanistas valencianos tanto es así que en el mismo mueble curvado iguala, y en algunos modelos supera, a las manufacturas de Viena, que fue, como ya sabemos, su cuna" 3 . 


\section{Sobre Salvador Albacar y Gil (1858-1928) y la escasa información antes del 1900}

Debió formarse como ebanista en los talleres de su padre. Según Martínez Ferrando el padre de Salvador, Pedro Albacar, procedente de Catalunya, "había sido discípulo de Caselles (Juan Caselles, 'el padre de la ebanisteria valenciana' en el siglo XVIII)" y se quedó a la muerte de este con su taller. En efecto, existen facturas de la década de 1860 emitidas bajo el nombre de "Albacar Hermanos" donde se indica "antes de Caselles" ${ }^{\text {. Desde }} 1880$ en los anuarios industriales aparecen como ebanistas "Albacar Hermanos" en la Plaza de San Francisco n 8 o números 7 y 10 . También según Martínez Ferrando, en la Exposición Regional de 1883 "llamaban muy justamente la atención los muebles de lujo de Albacar y Suay y los de madera curvada de Trobat [...] la última palabra de la ebanistería"6. Si bien podemos dar por cierto que su padre estaba activo antes de la fecha de dicha exposición no es hasta 1893 cuando se le autoriza a Salvador Albacar una máquina de vapor de 8 caballos. Desde 1897 la empresa se anuncia como "Salvador Albacar y Compañía". En 1899 el arquitecto Antonio Martorell y Trilles (1845-1930) construyó el mausoleo para la familia Albacar (Luis Albacar Tournier y Salvador Albacar y Gil).

En Valencia, Salvador Albacar vivía en la céntrica calle Grabador Esteve $\mathrm{n}^{0} 4$, edificio que todavía se conserva y en cuya verja de hierro se pueden leer todavía las letras "S" y "A" superpuestas. El tipo de casa donde vivía muestra que era un miembro destacado de la burguesía industrial valenciana de la época, como otros mueblistas con casas burguesas como Luis Suay y Ventura Feliu. Entre las famosas villas de Benicassim se encuentra "Villa Victoria", residencia de verano de don Salvador Albacar, cuya construcción se terminó en 1911 según se indica en la fachada principal de la Villa. Se trata de una edificación de estilo francés apta para el veraneo que empezaba entonces a ponerse de moda entre las clases adineradas de Valencia 7 . Albacar era, al parecer, todo un personaje de la localidad y no debían faltar las fiestas "de sociedad" en su villa (Fig. 1). 


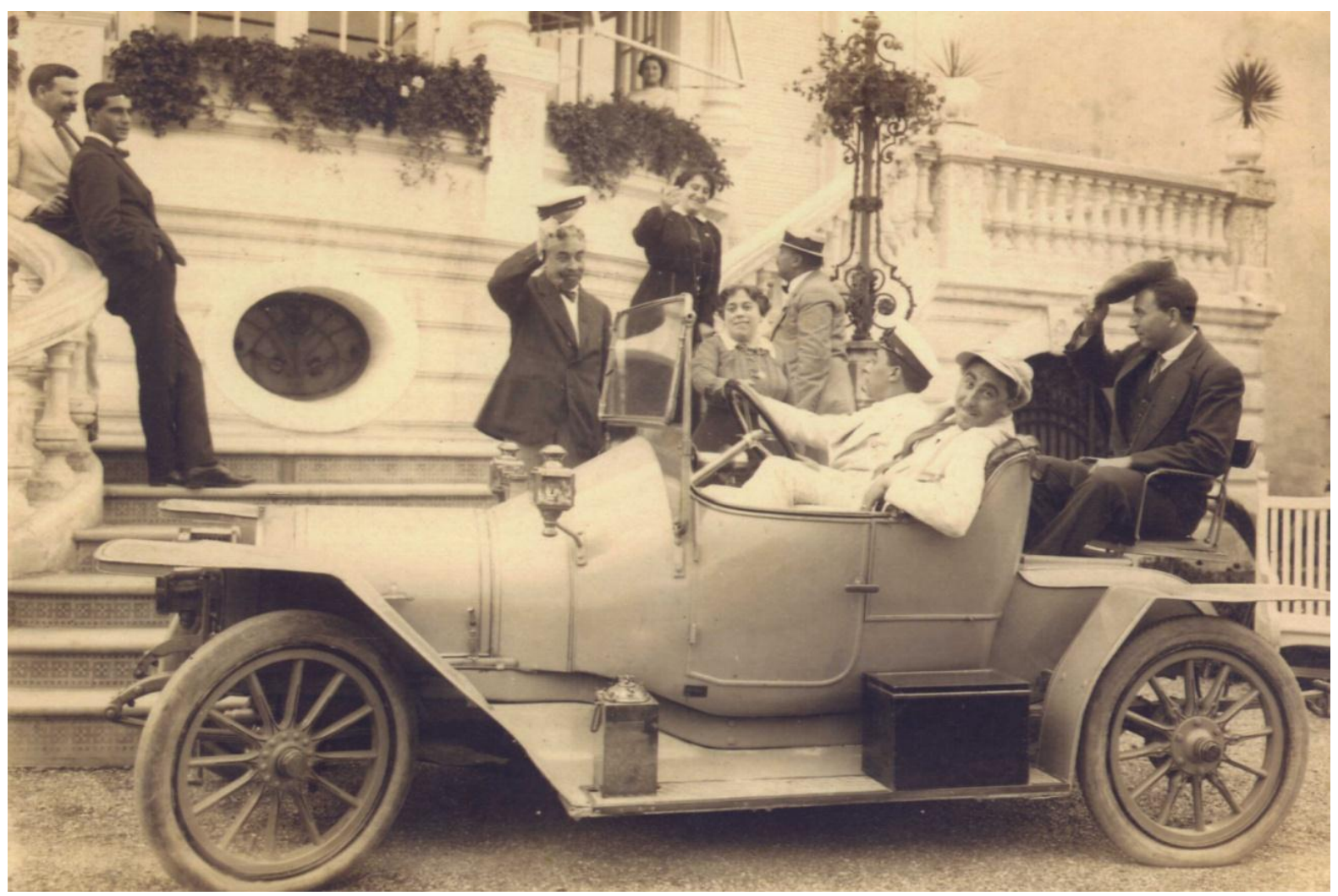

Fig. 1. Salvador Albacar (saludando con la gorra en las escaleras) en Villa Victoria. Fotografía del archivo del autor.

\section{La fábrica}

Salvador Albacar tenía la fábrica en el Camino del Grao de Valencia desde 1897. La numeración de la fábrica en la calle varió entre el $\mathrm{n}^{\circ} 31 \mathrm{y}$ el $\mathrm{n}^{\circ} 21$. El Camino del Grao (avenida del puerto) fue conocido en algúna travesía, hasta 1914, como calle Albacar. La fábrica fue hecha por el maestro de obras Vicent Alcayne (1828-1913) 8. El mismo año 1897 Albacar intentó introducir en España, sin éxito, la patente de Jacob y Josef Kohn de sustituir las espigas de madera en las patas delanteras de los asientos por piezas de rosca metálicas 9 así como un procedimiento para utilizar el cuero liso o repujado en los muebles de madera curvada. Por estas solicitudes podemos observar que mostraba el conocimiento de los avances que se producían en el extranjero. Debe destacarse en este sentido la importancia de la cercanía del puerto a efectos de importación de madera y muebles y de exportación de los mismos. El despacho y los almacenes los tenía, al menos desde 1902, en la plaza de Emilio Castelar $n^{\circ} 8$; actualmente la plaza del ayuntamiento de Valencia (Fig. 2). 


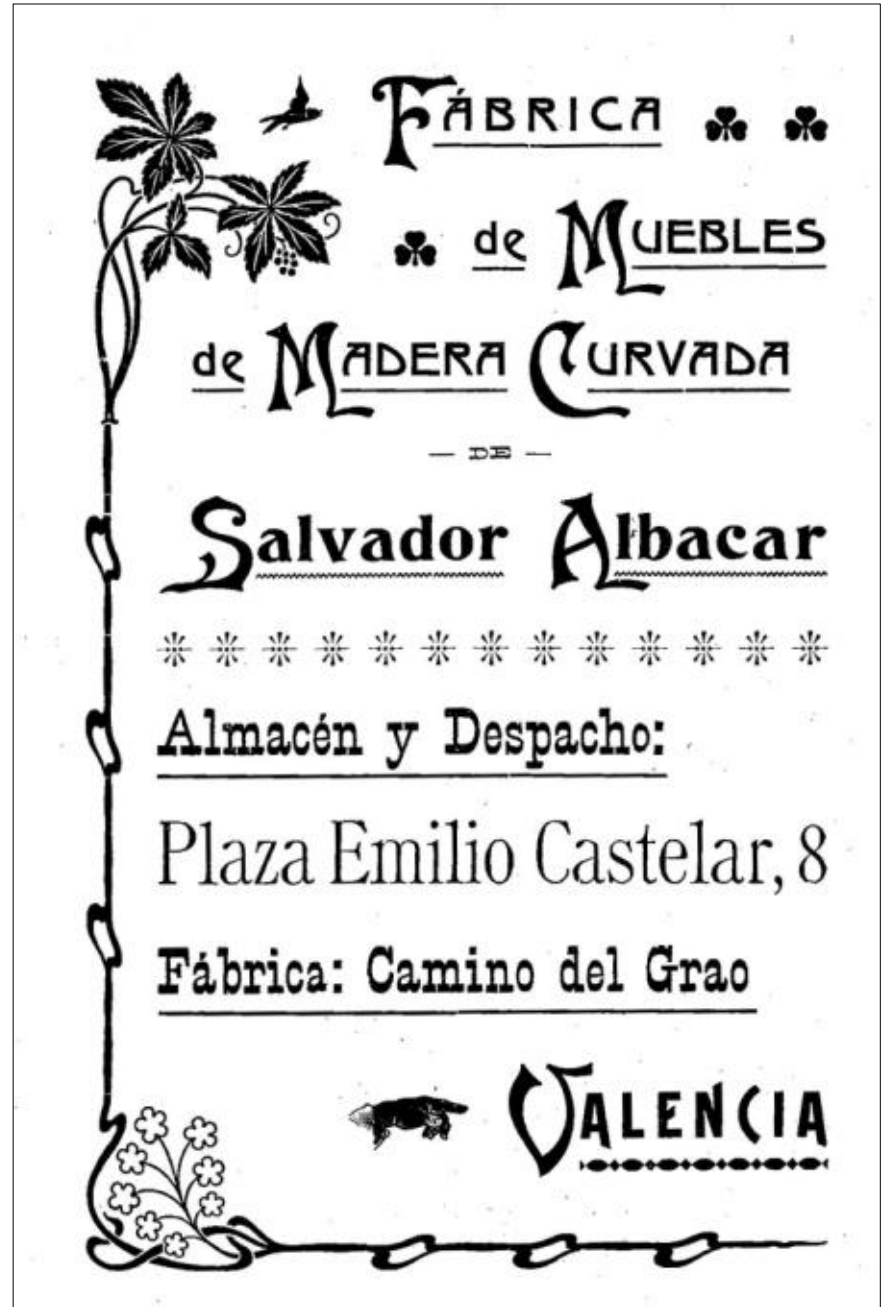

Fig. 2. Anuncio de Albacar. Almanaque Las Provincias, 1905

En una publicación de la época se relata que "(H)ace muy pocos años todos los muebles de madera curvada, de uso general en España y en sus antiguas colonias, procedían de Viena. Designábanse, y aún siguen designándose, con el título de muebles de Viena. Pues bien, el Sr. Albacar, que poseía en Valencia los mejores talleres de muebles de lujo y que surtía a toda España, incluso a los más acreditados establecimientos de la corte, concibió el proyecto de fabricar también aquellos muebles llamados de Viena. Sin utilizar un sólo operario extranjero, teniendo que descubrir procedimientos y hasta que inventar maquinaria, el Sr. Albacar, que había recorrido las mejores manufacturas de Europa, utilizó lo que la experiencia le había enseñado, lo que la observación pudo mostrarle, a veces valiéndose de hábiles sorpresas y estratagemas, y emprendió valerosamente la empresa"10. De este párrafo destacan, al menos, dos observaciones: una sobre la ausencia de obreros extranjeros lo cual nos hace pensar que debían existir acusaciones de la competencia al respecto y si no en su fábrica quizá en otras sí que operaban obreros de fábricas de Austria-Hungría que fueron a trabajar a Valencia. Este hecho explicaría, al menos en parte, la afamada perfección de algunos de los muebles curvados valencianos. Y la segunda observación se refiere al hecho de que Albacar debió probablemente viajar por Europa y dispondría de 
abundante información en cuanto a catálogos, técnicas, modelos etc. En cuanto a obreros en aquella época tenía unos cuatrocientos según los textos citados. Es interesante señalar que por el puerto de Valencia llegaban todo tipo de mercancías no sólo muebles de Viena sino también madera que se importaba desde Triestre según se menciona en el artículo de $E l$ liberal que hemos mencionado anteriormente. Era más barato importar la madera de AustriaHungría en barco que traerla de cualquier lugar de España. También podían, en este sentido, haber llegado obreros de las fábricas vienesas de mueble curvado, quizá de Bohemia, región de donde procedía el Vice-cónsul Honorario de AustriaHungría en Valencia, Franz Goerlich ${ }^{11}$.

En cuanto al proceso productivo en la fábrica, había división y especialización en el trabajo: "casi todas las labores se realizan a máquina pudiendo aquellas clasificarse en siete secciones, que son la de sierra, torneado, curvado, pulido, ajuste, barnizado y embalaje"12. En la misma publicación se describe así el curvado: "en el curvado se ve, como si, merced a un arte mágico, se puede dar a la madera, por fuerte que sea, la forma y retorcedura que se quiera, haciéndola tomar las más extrañas, y dejándola en tal condición de estabilidad y dura consistencia, que ya no vuelve a recobrar su primitiva forma, consintiendo antes en romperse que en tender a la posición recta que antes tuvo"13. Una elegante forma de explicar el curvado que consiste en fijar refuerzos metálicos para limitar al máximo la "rabia de la madera" cuando se la retuerce en caliente y después se enfría.

En la fábrica tenía un papel importante el hermano de Salvador, Juan Albacar: “...hermano del dueño de la fábrica, que es quien por hallarse al frente de los magníficos talleres de aquella, se encuentra en frecuente contacto con los obreros, siendo persona que a su completa identificación hasta con los menores detalles de la casa, une valiosos conocimientos técnicos y una práctica y competencia extraordinaria en esta clase de fabricaciones"14. También por la misma fuente conocemos el nombre del que hoy consideraríamos el diseñador de la empresa: José Artigas: "Ante el magnífico torno mecánico de perfilar, el monarca (Alfonso XIII en su visita a la fábrica) se detuvo, prestándole suma atención y demostrando conocer esta clase de aparatos, y al llegar al taller donde trabaja el dibujante de la fábrica, D. José Artigas, que es un inteligente y verdadero artista, el rey valiéndose del lápiz de pizograbar, dibujó una flor de lis en un mueble"15.

\section{Las patentes}

Las patentes más destacadas de Albacar son refuerzos de la estructura de las sillas, llamadas en el catálogo patente $\mathrm{n}^{0} 1 \mathrm{y} \mathrm{n}^{\circ} 2$.

PATENTE $\mathrm{N}^{\circ}$ 1. Refuerzo: patente de introducción $\mathrm{n}^{0} 31.41716$ por cinco años de "un aparato consistente en un refuerzo de madera curvada, de una sola pieza para las sillas llamadas de Viena", concedida el 6 de mayo de 1903. Nótese que se trata de una patente de introducción de una invención foránea, hecha por D.G. Fischel Hijos, el mueblista de Niemes (actualmente Mimon, en Bohemia) 
que tanta influencia tuvo en el catálogo de Albacar puesto que los primeros modelos del mismo están extraidos del catálogo de Fischel de 1889. En la memoria de la solicitud de patente se reconoce que es un invento extranjero que Albacar introduce en España.

PATENTE $\mathrm{N}^{\circ}$ 2. Traba: patente de invención $\mathrm{n}^{0} 31.875^{17}$ por veinte años por "un refuerzo en forma de S cruzada horizontal, de madera curvada, para las sillas llamadas de Viena", concedida el 31 de julio de 1903 y acreditada la práctica el 18 de septiembre de 1906. Hay una conocida fotografía de Unamuno en su habitación de la Residencia de Estudiantes donde aparece sentado en una silla con la traba $\mathrm{n}^{0} 2$ de Albacar ${ }^{18}$.

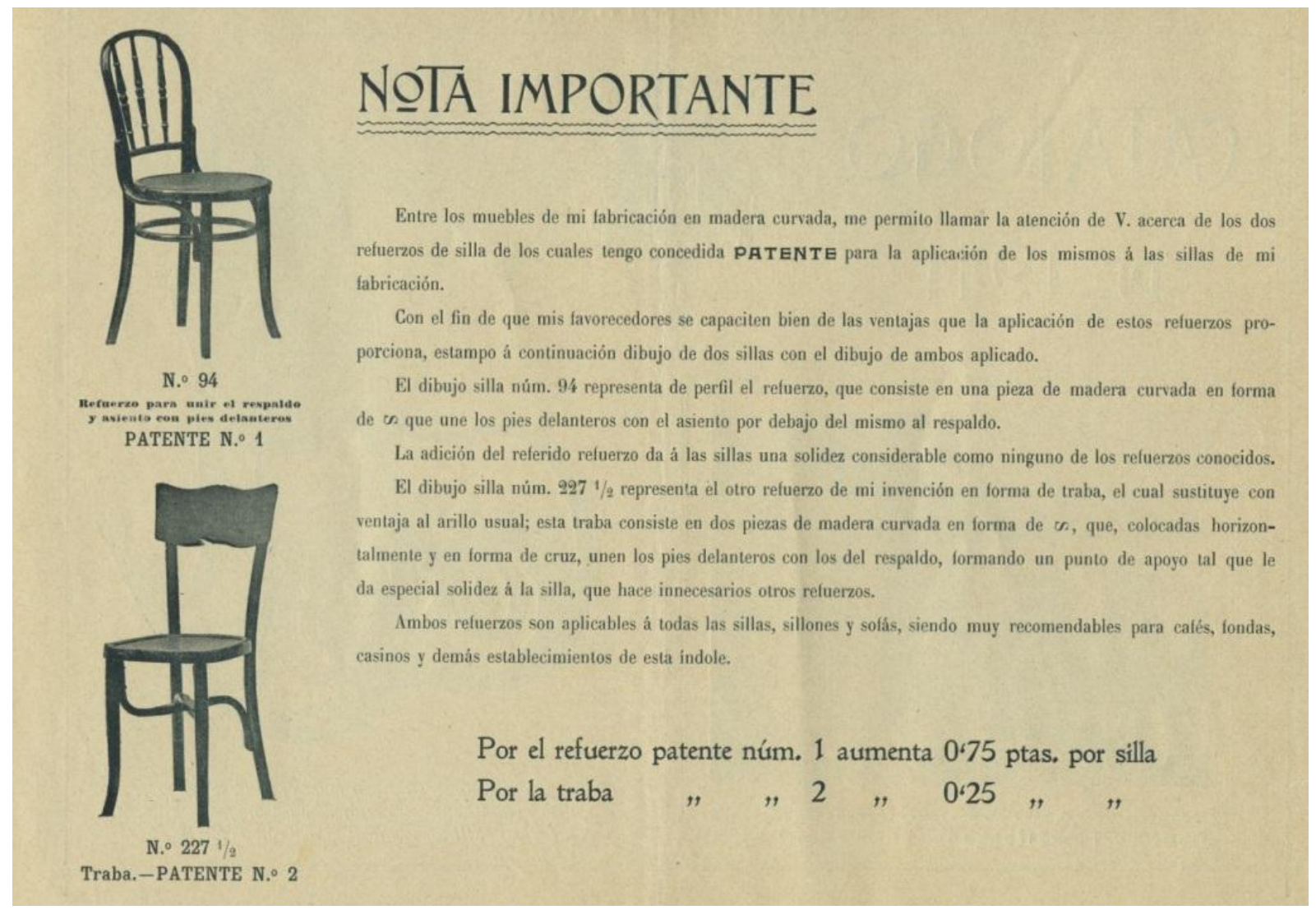

Fig. 3. Catálogo de Albacar de 1911. Página introductoria de patentes.

\section{El rey Alfonso XIII y la Fábrica de Albacar}

Consta que el Rey Alfonso XIII, en un viaje a Valencia, visitó la fábrica de Albacar el 12 de abril de 1905 junto a otras fábricas o establecimientos como la fundición de Climent y la fábrica de abanicos de Prior. En esa visita a Valencia el Rey puso la primera piedra de la Fábrica de Tabacos. Es una muestra de la importancia de la industria de Albacar en aquella época que fuera seleccionada para ser visitada por el Rey. Despues de la visita, en 1906, Albacar publicó un suplemento al catálogo de 1904 incluyendo la reproducción de una fotografía del Rey en su carruaje ${ }^{19}$. Consta también que con motivo de esta deferencia, Albacar 
le regaló al Rey dos mecedoras "en roble tallado y fileteadas en oro, con asiento y respaldo de cuero repujado a mano" por el Sr. Artigas, según consta en dicho suplemento del catálogo. Existen algunos anuncios de Albacar donde se utiliza el ejemplar de dicha mecedora como reclamo publicitario (Fig. 4). Se trata de una versión "Real", con el escudo de la casa, del modelo $\mathrm{n}^{0} 1$ de Hermanos Thonet, lanzado al mercado hacia 1860 y que es la mecedora del fabricante de Viena de más compleja fabricación. El rey en esta visita también puso una condecoración con la medalla de Isabel La Católica a cinco de los obreros de Albacar ${ }^{20}$.

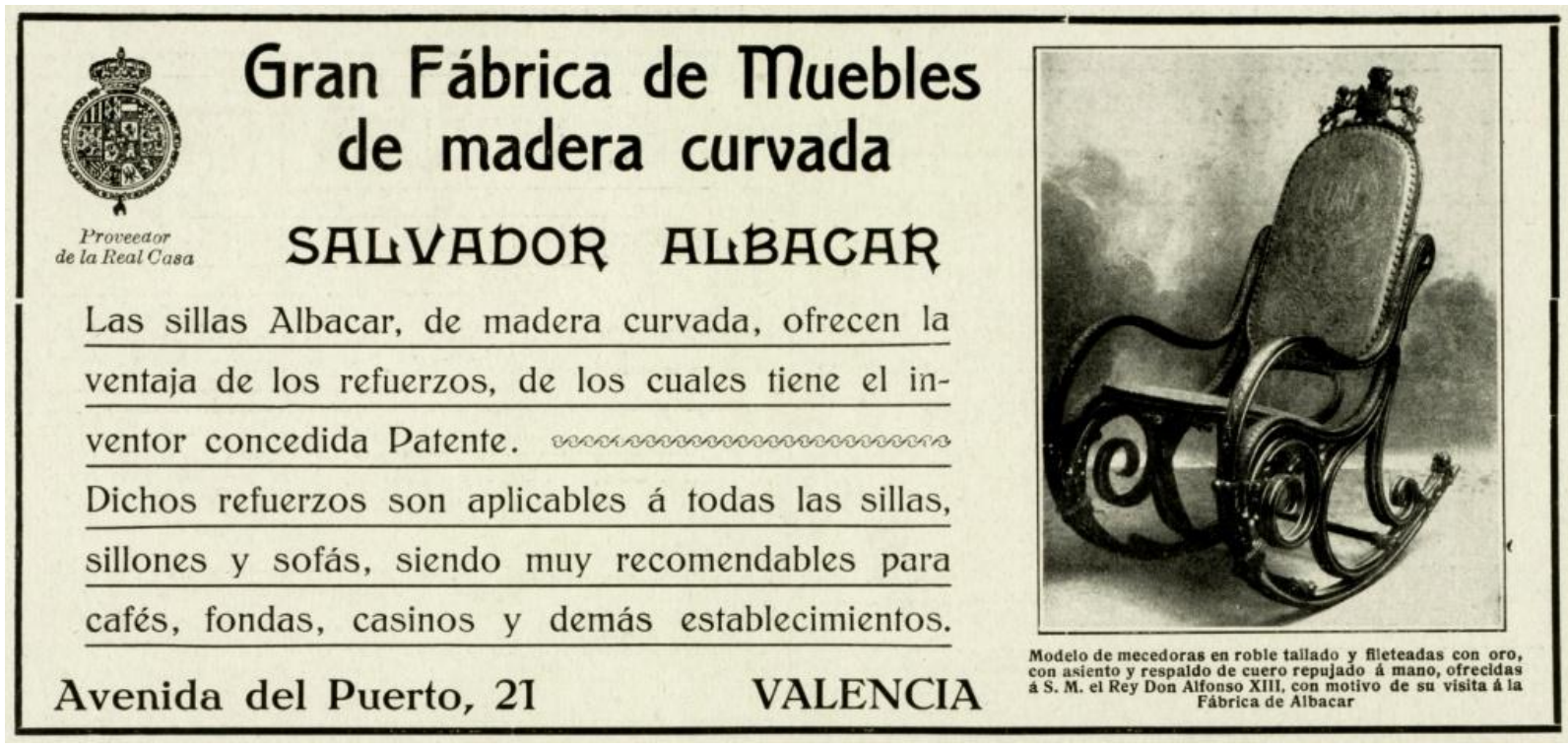

Fig. 4. Anuncio de Albacar. La esfera, 14 de julio de 1917, nª 185, p. 5.

\section{La viennoise}

El 16 de enero de 1906 Albacar registró como marca "La viennoise" (Fig. $5)^{21}$ como instrumento para distinguir los muebles llamados "de Viena" y para fomentar la exportación, quizá emulando a "La viennesse" de Nápoles que fabricaba también mueble curvado "tipo viena". Con esta marca se presentó en la Exposición Regional Valenciana de 1909 pero no consta que utilizara ninguna etiqueta con la marca para colocarla en sus muebles que no suelen llevar identificación alguna salvo la de "patente Albacar" cuando es el caso. En la solicitud de registro, de marzo de 1905, pero corregida en diciembre del mismo año, se encuentra la siguiente descripción: "La Marca en cuestión está compuesta por un círculo dentro del cual aparece un aguila caprichosa con dos cabezas y las alas extendidas. En la parte inferior del círculo y sostenida por las garras del águila hay una banderola sobre la que se lee la denominación de la Marca LA VIENNOISE. Por debajo de esta banderola aparece la extremidad de la cola del águila, pendiente de ella una cruz de ocho puntas que no tiene significación alguna, pues no se pretende representar una condecoración determinada. En la parte superior del círculo y tangente al mismo hay otra banderola sobre la que se leen las palabras VELLE EST POSSE22. Encima de esta banderola hay una 
corona sobre la cual hay un pájaro con las alas extendidas, debiéndose hacer constar que esta corona no tiene significación alguna heráldica. Inmediatamente en sentido convexo y encerradas en una banderola se leen las palabras SALVADOR ALBACAR-VALENCIA [en realidad sólo las iniciales $\mathrm{S}$ y A]. Esta Marca se estampará, de cualquier forma adecuada, sobre los muebles que ha de distinguir, así como sobre los envases que los contengan, etiquetas, rótulos, anuncios y sobre toda clase de papeles comerciales" 23 . Resulta de interés observar cómo en aquella época la expresión que se utilizaba siempre para designar este tipo de muebles era la de "mueble de Viena" y no la de "mueble Thonet" que se ha ido imponiendo posteriormente ${ }^{24}$.

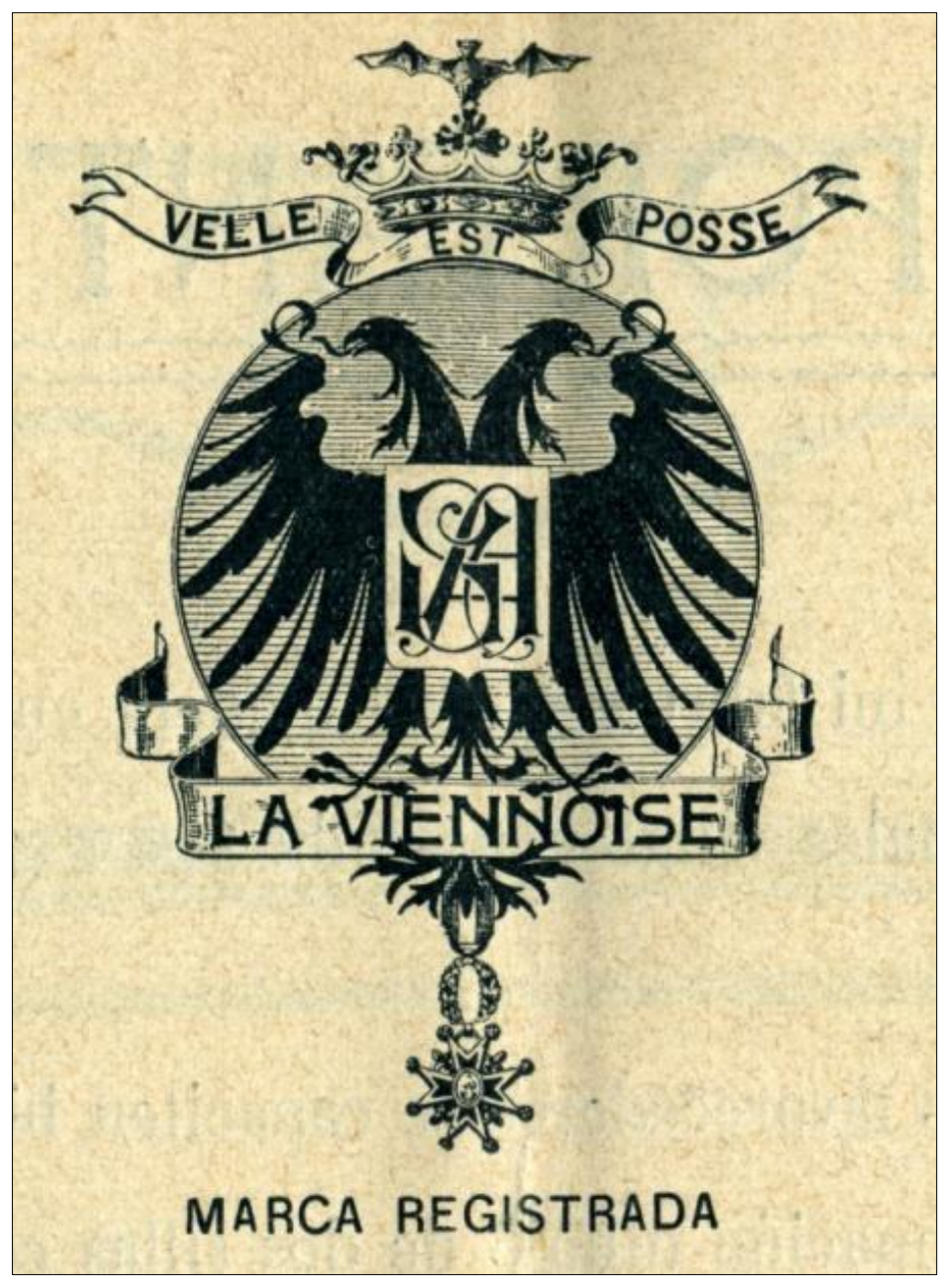

Fig. 5. Marca "La viennoise" (1906). Detalle del catálogo de Albacar de 1911.

\section{Exposición Regional Valenciana de 1909}

En cuanto a la participación en la Exposición Regional Valenciana de 1909 -elevada al rango de nacional en 1910, cuando se prorrogó- en un diario de la época se describe cómo era la instalación de Albacar que, por lo visto, debía presentar más mueble de ebanistería tradicional que curvado: “...se compone dicha instalación de tres bonitas habitaciones en las que se admiran un precioso despacho, un artístico ángulo de salón, un saloncillo Luis XVI, en rejilla, dorado 
antiguo, y un comedor en maderas de roble de estilo inglés, con las paredes tapizadas. D. Alfonso XIII saludó afectuosamente al Sr. Albacar y después de examinar aquellos artísticos trabajos aceptó el obsequio dedicado a la Reina, consistente en un lindísimo mueble tomado de otro que perteneció a María Antonieta"25.

El mismo año de la Exposición regional obtuvo Albacar una patente de invención por veinte años por "mejoras introducidas en la construcción de los muebles llamados de Viena y especialmente en las mecedoras" ${ }^{26}$. Se trata de uno de los diseños más populares y prácticos de mecedora de los industriales valencianos de mueble curvado que nunca se utilizó por los fabricantes de Viena. Su autor lo llamó "mecedora Exposición" en recuerdo de la Exposición regional de 1909 y quizá porque se exhibió en ella. Es interesante reproducir el argumento de la solicitud de patente presentada por Albacar: "muchas son las mejoras que se van introduciendo en la construcción de muebles de los llamados de Viena y especialmente en las mecedoras, pero aunque algunas de estas mejoras representan ciertas ventajas, ninguna ha dado completa satisfacción, puesto que todavía no se ha llegado a la simplificación deseada, obteniendo el mínimum de piezas y de costo. Con el presente invento creo haber realizado el ideal, puesto que he reducido, de tal modo, las piezas que componen una mecedora que es imposible simplificar más la construcción de las mismas y, por tanto, se reduce el coste a un mínimum imposible de superar"27. En efecto, el balancín, el brazo y el montante sólo están compuestos por dos piezas, evitándose espirales y decoraciones innecesarias. Su carácter práctico y funcional con ausencia de la tradicional espiral la ha llevado a ser confundida con modelos Thonet de corte funcionalista ${ }^{28}$.

Debe señalarse que la gran mayoría de mecedoras producidas en Valencia, como esta que comentamos, llevan una pieza a la que se ha llamado "estabilizador valenciano", un medio aro que une los dos lados del asiento con la barra estabilizadora delantera para evitar que con el uso la mecedora se escore hacia los lados. Se trata de un refuerzo que no se encuentra en las mecedoras hechas en Viena ${ }^{29}$. Que la mecedora "exposición" era uno de los productos más populares de Albacar se muestra con el hecho de que aparece en la portada del catálogo de 1911 (Fig. 6). 


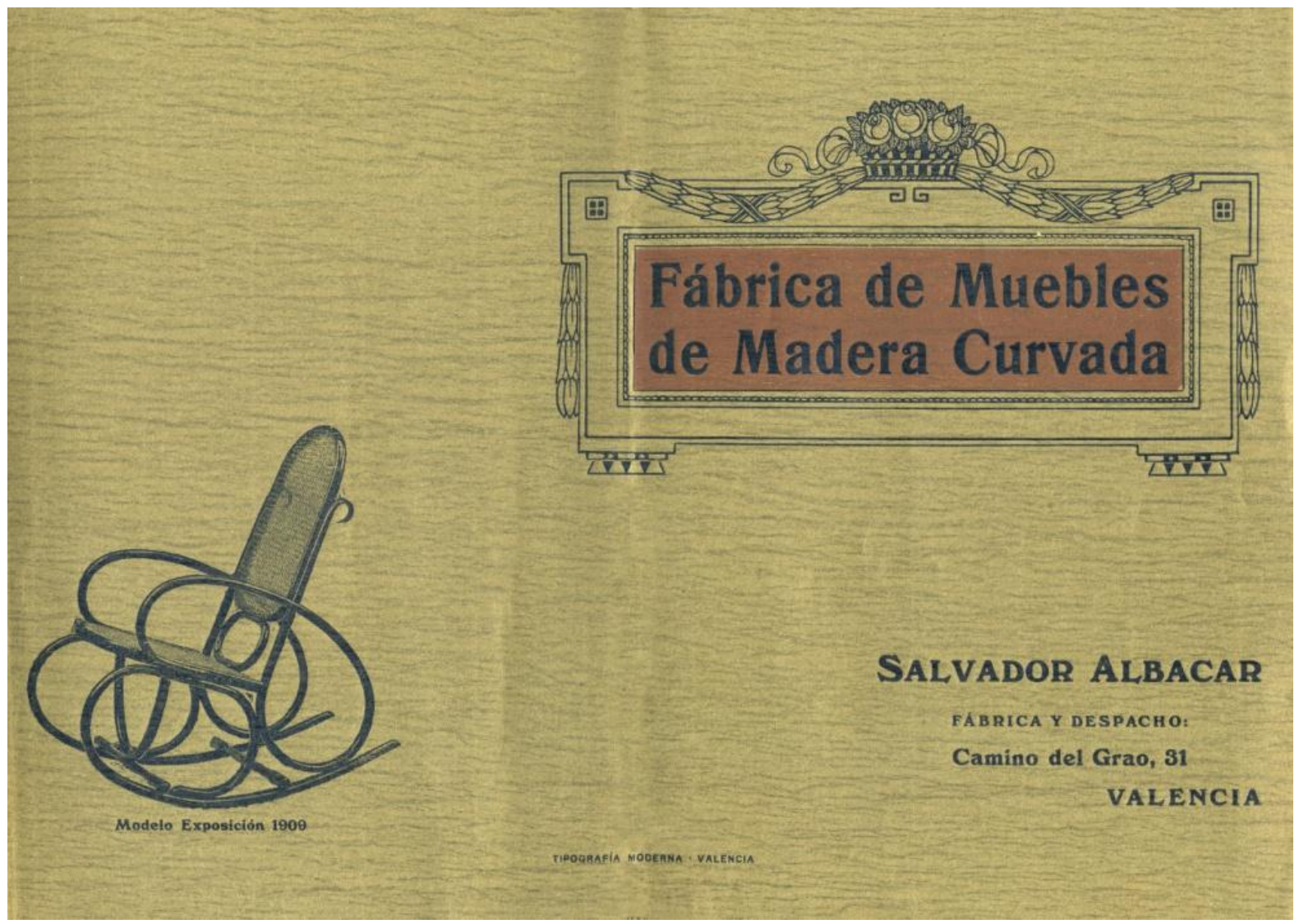

Fig. 6. Salvador Albacar. Catálogo de 1911. Portada con la mecedora "Exposición".

\section{La sucursal del número 10 de la calle Balmes}

Ya antes de la Exposición regional, hacia 190830, Albacar instaló una sucursal en el número 10 de la calle de Balmes de Barcelona a cien metros a la vista de la tienda de "Hermanos Thonet", en la calle de Pelayo $\mathrm{n}^{\circ}$ 40. Este dato es importante porque Barcelona era un punto de venta crucial de mueble originario de Viena en España y para su exportación a Sudamérica. A partir de ese momento se desatará una competencia feroz entre los vendedores de muebles vieneses de Barcelona (de los fabricantes Thonet y Kohn especialmente) y los mueblistas valencianos, sobre todo el citado Albacar, pero también Luis Suay y Ventura Feliu, que operaban a través de los Grandes Almacenes "El Siglo". Fue a partir de la edición del catálogo de 1911 cuando Albacar consiguió suculentos contratos en Barcelona y cuando la expansión de la empresa fue mayor. En el apartado de establecimientos con mobiliario de Albacar vemos que tuvo mucha aceptación entre comercios de Barcelona y grandes salas de fiestas y restaurantes. Hay que tener en cuenta que a partir de 1914, cuando se rompieron por la Primera Guerra Mundial las vías de comercio con Austria, el mueble curvado valenciano tenía una posición privilegiada en el mercado de Barcelona ${ }^{31}$. 
Entre la lista de establecimientos que hemos podido identificar (por la traba) con mobiliario, especialmente sillas, de Albacar, se encuentran algunos importantes (por su volumen) de Barcelona y sus alrededores: el Hotel Regina, el restaurante del casino de la Arrabasada, el salón de fiestas del Tibidabo, todos estos con la patente de traba en forma de $\mathrm{S}$ cruzada horizontal. También en Barcelona la tienda de camisas Francisco Puig (Pelayo 32, 1913), la sede de la Sociedad de Atracción de Forasteros (1913); el Hotel Subur de Sitges (Fig.7). En Valencia, el Gran Restaurante Miramar, el comedor del Casino-Restaurante Las Arenas; la cervecería-café "El león de oro". Los hoteles Royal y Simón de Sevilla, a través del examen detallado de las postales y las fotografías puede llegar a identificarse -siempre será una aproximación- el fabricante de las sillas correspondientes.

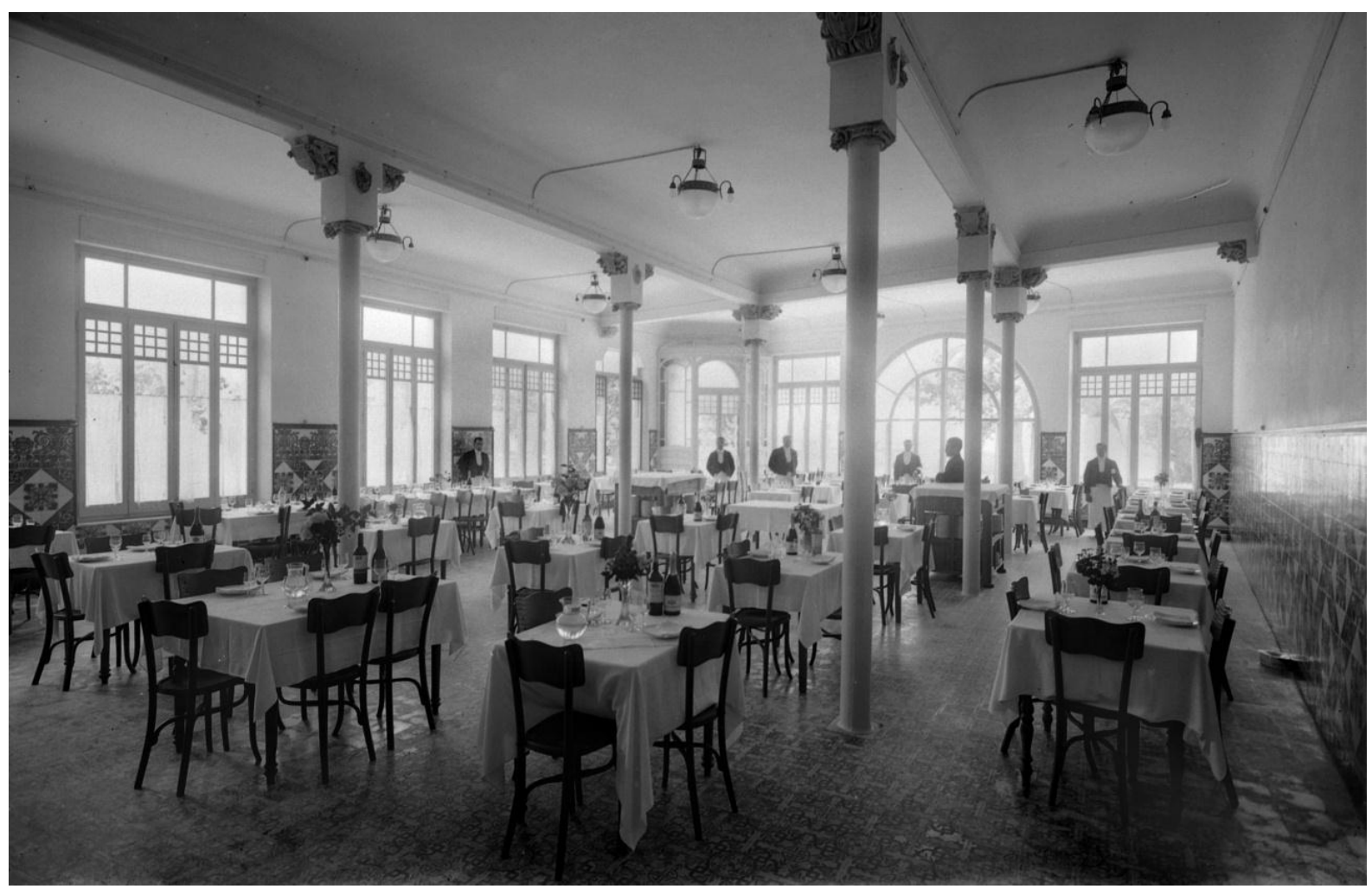

Fig. 7. Comedor del Hotel Subur de Sitges cuyas sillas llevan la traba Albacar. Fotografía de L. Roisin (1917). Arxiu Històric del Institut d'Estudis Fotogràfics de Barcelona.

\section{Los modelos}

Por otra parte, en su gran mayoría los modelos del catálogo de 1911 corresponden a -o están inspirados en- modelos de fabricantes vieneses, no de Hermanos Thonet, sino precisamente de D.G. Fischel Hijos y de Jacob \& Josef Kohn, ambos competidores en Viena. No obstante, podemos destacar por cierta originalidad o manifestación de destreza en su ejecución, algunas piezas del catálogo como una cuna de madera curvada, un ejemplar de la cual puede verse en el Museo de La Granja de Esporles (Mallorca) (Fig. 8) y que recuerda a las cunas de Jacob \& Josef Kohn, pero Albacar era el único entre los mueblistas 
valencianos que hacía así, con estos rulos, este mueble tan fino y llamativo ${ }^{32}$. La mecedora $n^{\circ} 6$, que es el modelo que aparece en una fotografía de Serra (Arxivo Fotográfico de Barcelona) donde se ve al historiador, artista y crítico de Arte Feliu Elias -llamado “Apa”-, en su taller (Fig. 9). El sofá n ${ }^{0} 165$ del catálogo de Albacar de 1911, un ejemplar del cual se reproduce sin datos de origen en el libro sobre Thonet de Alexander von Vegesack como representativo del art nouveau en materia de muebles de madera curvada ${ }^{33}$. Esta última pieza es destacable por el trabajo decorativo de la chapa calada del respaldo. Como es sabido, la introducción del contrachapado en el mueble curvado permitió una adecuación de las formas a los gustos por los estilos, incluido en su época el modernismo. Sin ánimo exhaustivo, también son destacables algunos de sus percheros en los que junto a los componentes de madera curvada, insertaba piezas de cerámica, dándoles un toque estético costumbrista, e introduciendo así otros elementos propios de la industria regional.

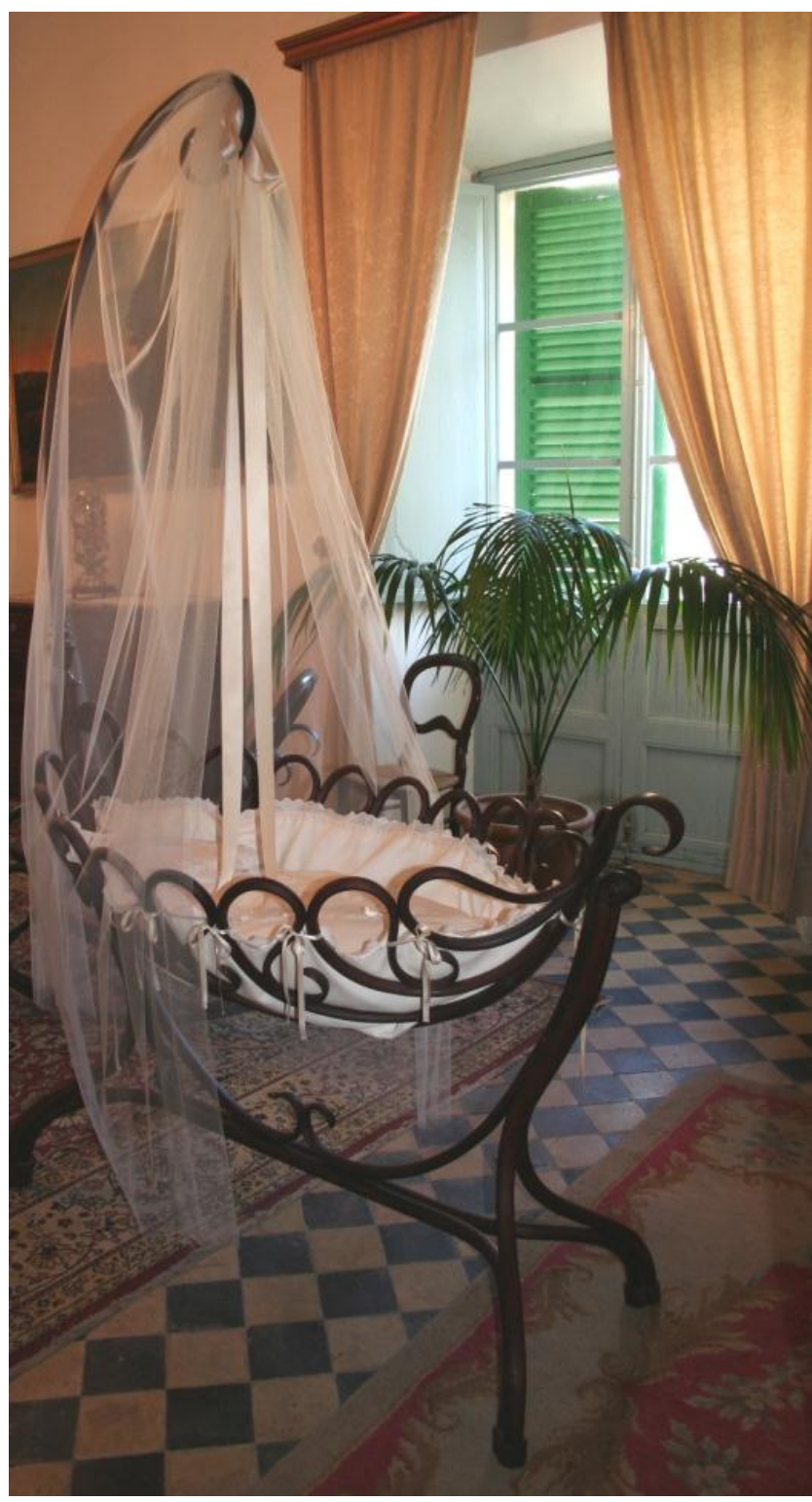

Fig. 8. Cuna de Albacar. Museo de La Granja de Esporles (Mallorca). 


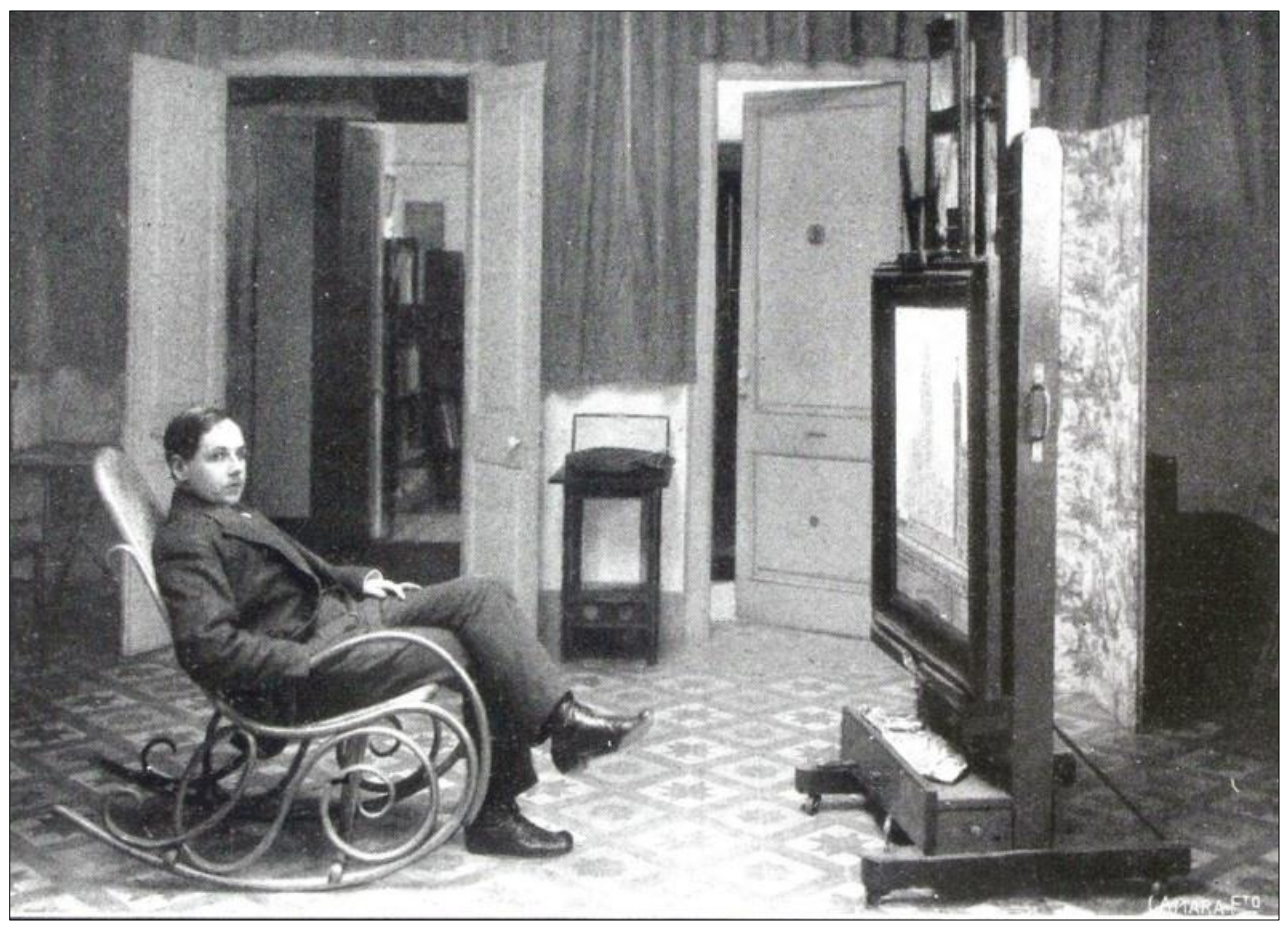

Fig. 9. Feliu Elias retratado en su taller. La esfera, 14 de abril de 1917, nº 172. Fotografía Serra.

En conclusión, Salvador Albacar fue un fabricante y decorador de los más importantes de Valencia a finales del XIX y principios del Siglo XX.

\section{NOTAS}

\footnotetext{
${ }^{1}$ Sobre el desarrollo de la industria del mueble curvado vid. ALVERÀ, Alessandro, "Michael Thonet and the development of bent-wood furniture: from workshop to factory production", en: OSTERGARD, Derek (Ed.), Bent Wood and Metal Furniture, 1850-1946, Chicago: The American Federation of Arts, 1987, pp. 33-52. La bibliografía sobre Thonet y el mueble curvado es extensa y se han publicado ya diversos catálogos. Vid. WILK, Christopher, Thonet: 150 years of Furniture, London: Barron's, 1980. Las últimas publicaciones relevantes con bibliografía son las de RENZI, Giovanni y Chiara, Curve e Biondi Riccioli Viennesi. Mobili in faggio curvato da Michael Thonet ad Antonio Volpe, Milano: Silvana Editoriale, 2000, (bibliografia esencial en p. 121) con reproducción de tres catálogos de Thonet (1891), Kohn (1906-1907) y Fischel (1911); y OTTILINGER, Eva (HG)., Gebrüder Thonet. Möbel aus Gebogenem Holz, Wien: Böhlau, 2003, donde se reproduce el catálogo de Thonet de 1885. Sobre Kohn vid. VIVES CHILLIDA, Julio, Jacob \& Josef Kohn: una mirada desde Barcelona, Barcelona: Editorial La plana, 2006 (bibliografía y cita de catálogos sobre mueble curvado en pp. 140-143). Sobre Fischel cfr. SIMONIKOVÁ, Jaromira, (Ed.), D.G. Fischel Söhne. Niemes-Wien. Der Katalog von 1915, München: Ketterer Kunst Verlag, 1992, con una introducción al catálogo en inglés y alemán.

${ }^{2}$ Vid. en general: LECUONA M. y MARTÍNEZ, M., "Encanto y proceso modernizador del mueble curvado", en MUÑOZ, M. (ED.), El modernismo en la Comunidad Valenciana, Valencia: Diputación de Valencia/Centro Cultural La Beneficiencia, 1998, pp. 155-181. Sobre Ventura Feliu vid. VIVES CHILLIDA, Julio "La imagen de la fábrica de muebles curvados hijo de Ventura Feliu (Valencia)", comunicación para las "XII Jornadas Internacionales de Patrimonio Industrial"- Diseño, imagen y creatividad en el patrimonio industrial-, Gijón, 30 de septiembre-2 de octubre de 2010, 2011, pp. 337-349.
} 
${ }^{3}$ MARTÍNEZ FERRANDO, E., "El Mueble Curvado" en: Cuatro Industrias Valencianas de abolengo, Valencia: Cámara de Comercio, Industria y Navegación de Valencia, 1953 (Reedición del libro de 1933), p. 105.

${ }^{4}$ Hay una calle "Ebanista Caselles", en Valencia. En el callejero del diario "Las Provincias" (7 de marzo de 2008) bajo el título de "el arte de la madera" se dice que Juan Caselles fue "un ebanista muy acreditado en su oficio. Construyó en su almacén de muebles del Nuevo Gusto una mesa velador de palo santo, con embutidos de acebo, que se hizo famosa por su valor artístico. El reputado ebanista, que trabajó para el Teatro Principal, murió en Benicassim al ser derribada por las aguas de un torrente la diligencia en la que viajaba".

${ }^{5}$ Ad. ex. Anuario del comercio, de la industria, de la magistratura y de la administración, 1885, p. 1593.

${ }^{6}$ MARTÍNEZ FERRANDO, E., op. cit., p. 107.

${ }^{7}$ Se desarrolla en esta residencia de verano el argumento de la novela de VÁZQUEZ BAYARRI, Victor, Villa Victoria. Los lenguajes callados publicado por De las Ediciones Libertarias en 1991. En la portada de este libro puede apreciarse la famosa mecedora regalada a su Majestad el Rey en su visita a la fábrica en 1905. Pueden verse fotografías de Villa Victoria directamente consultando en internet.

${ }^{8}$ El dato está extraído de: GARCÍA MONERRIS, Carmen, De l'ofici a la fàbrica. Una familia industrial valenciana en el canvi de segle, La maquinista valenciana, Universitat de València, 2000, pp. 27-28.

${ }^{9}$ Cfr. VIVES CHILLIDA, Julio, Jacob \& Josef Kohn..., op. cit., la patente en p. 87.

10 "Valencia industrial. Una gran fábrica de muebles de madera curvada. Propietario D. Salvador Albacar", El liberal, Domingo 22 de mayo de 1904. En el artículo se incluye un dibujo-retrato de Salvador Albacar. Vid. también "Gran Fábrica de muebles de madera curvada de don Salvador Albacar. Valencia", Revista ilustrada de Banca, Ferrocarriles, Industria y Seguros, n 17, 1905, pp. 423-425.

${ }^{11}$ Cfr. sobre este grupo social de Valencia: RANCH, Eduardo, "Carta de un cuarentón adelantado al «setentón» de Las Provincias sobre unos valencianos bohemios", Valencia Atracción, año XXI, n 132, Ayuntamiento de València, enero de 1946, pp. 2-5.

${ }^{12}$ Revista ilustrada..., op cit., p. 424.

${ }^{13}$ Ibid.

${ }^{14}$ Ibid.

${ }^{15}$ Ibid.

${ }^{16}$ Boletín Oficial de la Propiedad Industrial (en adelante BOPI) $\mathrm{N}^{\circ}$ 403, 1903.

${ }^{17} B O P I \mathrm{~N}^{\circ} 408,1903$. En cuanto a mecedoras el 14 de febrero de 1907 patentó (n $\left.{ }^{\circ} 39.807\right)$ un modelo: "un nuevo sistema de construcción de las mecedoras llamadas de Viena"-BOPI $\mathrm{N}^{\circ} 494$, 1907- que no consta que produjera comercialmente dado que no se encuentra en los catálogos ni ha sido visto nunca en el mercado. No obstante, no se puede dejar de reconocer en cuanto a las mecedoras el intento de superación y perfeccionismo de la casa Albacar.

18 “Miguel de Unamuno en la Residencia de Estudiantes", La esfera, 24 de enero de 1914, no 4, p. 8.

${ }^{19}$ En este artículo manejamos dos catálogos de venta de Salvador Albacar: el de 1904 con suplemento de 1906 (41 páginas) -fotocopias del archivo del autor- y el de 1911 (53 páginas) de la Biblioteca de Foment del Treball Nacional (Barcelona), copia del original.

20 "Exposición Regional Valenciana. Instalación de la Gran Fábrica de Muebles de D. Salvador Albacar", El Heraldo de Madrid, 2 de junio de 1909.

${ }^{21}$ BOPI N $\mathrm{N}^{\mathrm{4}} 467,1906$.

${ }^{22}$ Velle est posse significa "Querer es poder".

${ }^{23}$ Madrid, 30 de diciembre de 1905.

${ }^{24}$ Razones comerciales militan en favor de la denominación "muebles Thonet". En España es ya un clásico el libro de CANDILIS, G., Muebles Thonet. Historia de los muebles de madera curvada, Barcelona, Gustavo Gili, 1980, que, en su versión original se titulaba Bugholzmöbel-Meubles en bois courbé-Bent wood furniture, Suttgart: Karl Krämer Verlag, 1980. Nosotros preferimos la denominación de mueble curvado o mueble de Viena por tener más rendimiento explicativo desde el punto de vista histórico dado la pluralidad de fabricantes que existieron.

25 "La Exposición de Valencia. Instalación de la Casa Albacar": El liberal, 3 de junio de 1909, p. 2. Cfr. Guia y catálogo oficial. Exposición Regional Valenciana 1909, p. 214. Sobre la importancia de la industria de la madera y el mueble en el contexto de la Exposición puede consultarse en la internet: SÁNCHEZ ROMERO, Miguel 
Ángel, La industria valenciana en torno a la Exposición Regional de 1909. Tesis doctoral, UPV, Valencia, 2009, pp. 165-179.

${ }^{26}$ Patente $\mathrm{n}^{\mathrm{o}} 46.479$ (22 de noviembre de 1909).

${ }^{27}$ Expediente n ${ }^{\mathrm{o}} 46.479$, de 11 de octubre de 1909. Archivo Histórico de la Oficina Española de Propiedad Intelectual.

${ }^{28}$ Aparece una fotografía de la mecedora "Exposición" de Albacar en el libro de MASSOBRIO, Giovanna y PORTOGHESI, Paolo, La seggiola di Vienna. Storia dei mobili in legno curvato, Torino, Martano Editore, 1980, sección fotográfica de Maurizio di Puolo dedicada a la "Variación de las secciones resistentes" (s.p.).

${ }^{29}$ Cfr. VIVES CHILLIDA, Julio, Catàleg de la col.lecció de Balancins, Vinaròs, Fundació Caixa Vinaròs, 2013, p. 24.

${ }^{30}$ Anuario Riera, 1908, no 1, p. 1020.

${ }^{31}$ Cfr. Respecto a Valencia: SOLER i MARCO, Vicente, Guerra i expansió industrial. País Valencià (19141923), Valencia: Alfons el Magnànim, 1984.

${ }^{32}$ Una cuna de madera curvada de J. \& J. Kohn de este estilo se encuentra en el Museo del Diseño de Barcelona.

${ }^{33}$ VON VEGESACK, Alexander, Thonet. Classic Furniture in Bent Wood and Tubular Steel, Nueva York, Rizzoli, 1997, p. 86. El modelo reproducido en este libro aparece en el catálogo de Albacar de 1911 (p. 12) y nunca se ha visto en catálogo alguno de muebles de Viena de Thonet o de otros fabricantes.

Fecha de recepción: 24 de mayo de 2014

Fecha de revisión: 3 de julio de 2014

Fecha de aceptación: 27 de julio de 2014 